\title{
A Randomized Controlled Trial of Brain-Activating Rehabilitation for Elderly Participants with Dementia in Residential Care Homes
}

\author{
Tetsuya Yamagami $^{\text {a }}$ Yoshifumi Takayama $^{\text {b }}$ Yohko Maki $^{c}$ \\ Haruyasu Yamaguchic ${ }^{\mathrm{C}}$ \\ a School of Health Care, Takasaki University of Health and Welfare, Takasaki, \\ bWisnet Co., Ltd., Saitama, and ' Gunma University Graduate School of Health Sciences, \\ Maebasi, Japan
}

\section{Key Words}

Alzheimer's disease $\cdot$ Brain activity $\cdot$ Dementia care $\cdot$ Non-pharmacological therapies •

Randomized clinical trials $\cdot$ Rehabilitation $\cdot$ Reminiscence therapy

\begin{abstract}
Background/Aims: We aimed to prove the effectiveness of brain-activating rehabilitation for dementia, which consisted of 5 principles: pleasant atmosphere, communication, praising, social role, and supportive care. Methods: The design was a randomized controlled trial that was not blinded. Fifty-four elderly participants with dementia (mean age: 85.2 years) were selected. Intervention based on the 5 principles of brain-activating rehabilitation was conducted for $1 \mathrm{~h}$, twice a week, for 12 weeks (24 sessions). The control group had no treatment. Outcome measures consisted of two observation scales, namely sum of boxes in clinical dementia rating (CDR$\mathrm{SB}$ ) and the multidimensional observation scale for elderly subjects (MOSES), and two cognitive tests: the Hasegawa dementia scale revised (HDS-R) and trail making test A. Results: Repeated measure ANCOVA showed a significant interaction for total score of CDR-SB $(F=7.190, p=0.015)$ and MOSES ( $F=4.525, p=0.038)$. There were no significant changes in the two cognitive test scores. Conclusion: Intervention based on the principles of brain-activating rehabilitation was effective in maintaining and improving daily life functions in elderly participants with dementia in residential care homes.

Copyright $\odot 2012$ S. Karger AG, Basel
\end{abstract}




\section{Introduction}

Rehabilitation for dementia, such as reminiscence therapy, reality orientation, cognitive rehabilitation, and physical activity, has an important role in delaying disease progression and functional decline. Studies on rehabilitation for dementia have focused on the differentiation of each technique (e.g. reminiscence therapy, reality orientation) and a comparison of their effects. However, Cochrane reviews on non-pharmacological interventions have highlighted the insufficiency of the available evidence [1-3]. We thought that the principles of intervention are much more important than each technique of intervention because intersubjectivity between participants and therapists/care staff has a much greater influence than each technique used. When the effects of three kinds of interventions, namely group reminiscence therapy, individual reminiscence therapy, and a group games, were compared in residential care homes, group reminiscence therapy improved memory performance and group games improved well-being, whereas individual reminiscence therapy was less effective. These findings suggested that group membership plays an important role in maintaining and promoting health and well-being [4]. We proposed a new principle of rehabilitation for dementia, brain-activating rehabilitation (BAR) [5], which consists of 5 principles: (1) enjoyable and comfortable activities in an accepting atmosphere; (2) activities associated with empathetic two-way communication between staff and participant, as well as between participants; (3) praising participants to enhance motivation; (4) offering social roles to participants that enhance their remaining abilities, and (5) supportive care to prevent failure, which causes confusion of participants. In fact, BAR was conducted as a combination of several techniques (e.g. reminiscence therapy, reality orientation, games, physical activity, crafts, cooking, and singing) to suit the participants based on these 5 principles. BAR was expected to enhance participants' motivation and maximize the use of their remaining functions and prevent the disuse of functions [5]. BAR was expected to enable participants to recover both a desire for life and their self-respect. Enhanced motivation induced by BAR can lead to amelioration of the behavioral and psychological symptoms of dementia and improvements in activities of daily living [6]. Improvements in cognitive function would also be expected through BAR [7].

In this study, we conducted intervention based on the principles of BAR for elderly participants with dementia as a randomized controlled trial to prove the effectiveness of BAR.

\section{Methods}

\section{Participants}

Fifty-four elderly participants in four residential care homes (group living homes) were selected on the basis of the following criteria: (1) being diagnosed with dementia; (2) without severe auditory and visual impairments, and (3) being able to engage in a simple activity or a brief conversation.

\section{Randomization}

At the end of the initial baseline assessment, we randomly divided participants into intervention and control groups in each residential care home, so that each intervention or control group was composed of four small groups. We used stratified randomization according to the Hasegawa dementia scale revised (HDS-R) [8], which is similar to mini-mental state examination (MMSE) and has a total score of 30 , to equalize the severity of dementia between the two groups. Finally, 54 participants were randomly allocated to the intervention group $(\mathrm{n}=28)$ or control group $(\mathrm{n}=26)$ (fig. 1$)$. 
Fig. 1. Participant flow diagram.

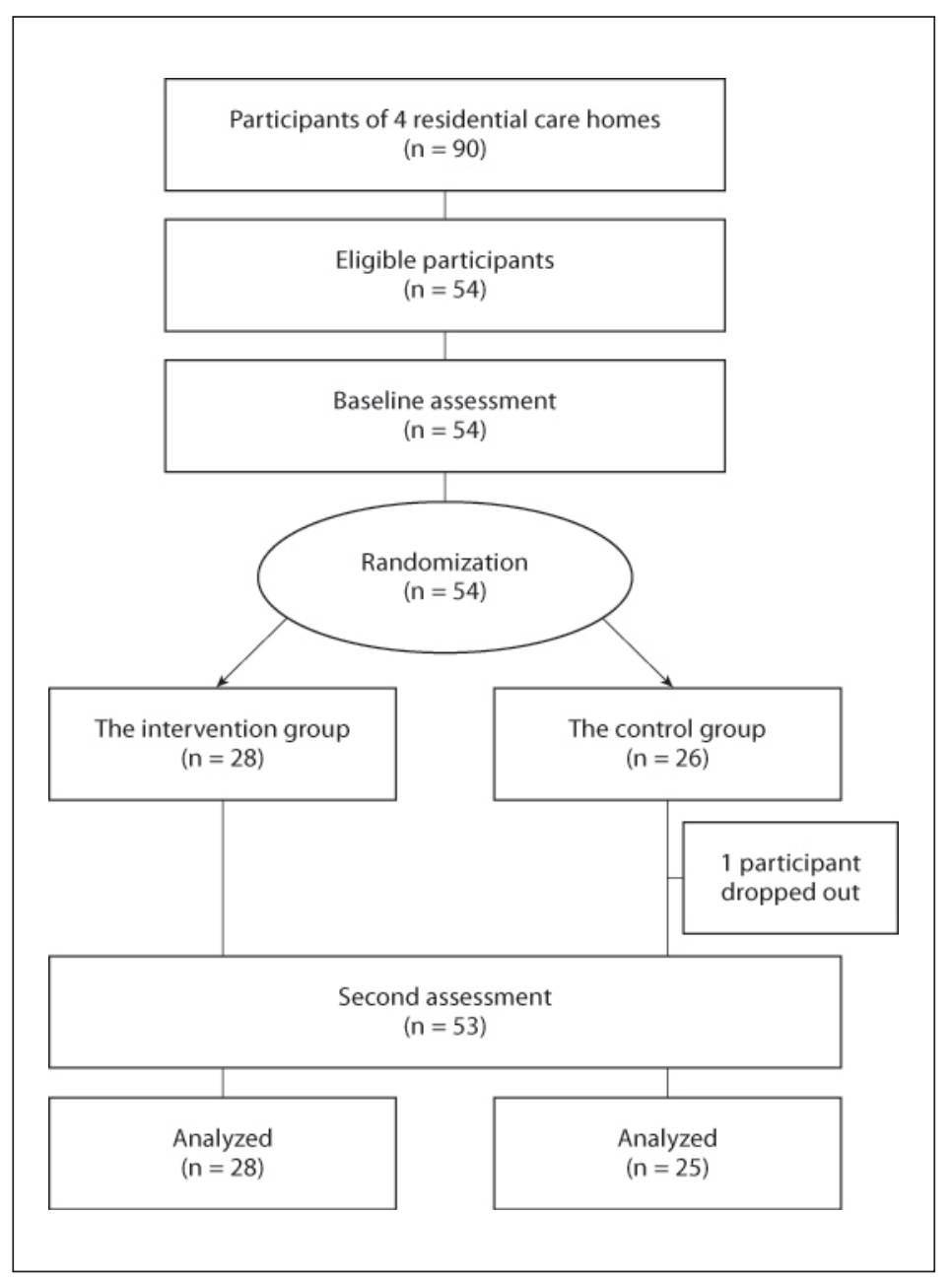

\section{Intervention}

A total of 24 sessions were conducted in each group for $1 \mathrm{~h}$, twice a week, for a 12 -week period. In this study, intervention based on principles of BAR combined reality orientation and various activities (e.g. cooking, singing, and sewing) along with reminiscence therapy. In the baseline assessment, we collected information on life histories and specialties from the participants to select enjoyable topics in the sessions (table 1). The intervention staff consisted of one leader and two vice-leaders for each group. The staff of each residential care home had studied the principles of BAR and specifically learned the guidelines about attitude and communication for $4 \mathrm{~h}$, and they played the roles of leader and vice-leaders by rotation. The researcher contributed to serve the same contents of the sessions for four groups. Throughout the session, staff had to accept and share the world of the participants, regardless of whether it was true or not (the first principle: pleasant atmosphere). At the same time, they organized the participants so that each participant could socially interact with other participants (the second principle: communication). When a participant seemed to make a mistake, or not to understand, staff acted to prevent the mistake (the fifth principle: supportive care). After each session, an evaluation meeting was held to improve the skills of the staff. In total, 41 members of staff were involved in the intervention (mean age: 30 years; duration of work experience: 4.9 years; mean number of sessions: 4.5$)$. 
Table 1. Topics of BAR sessions

\begin{tabular}{ll}
\hline Topics & Tools \\
\hline Cooking rice & rice kettle, furnace, measure, charcoal \\
Traditional games & beanbag for juggling, cup-and-ball toy, propeller \\
Pickled vegetables & rice bran, earthenware pot, salt, water \\
Washing & cloth, washing board, washing powder \\
Sewing duster & mortar, mallet, steam pot, glutinous rice \\
Making rice cakes & rice bran, rice bran bag, washbowl \\
Rice bran & mortar and pestle, taro potato, sesame \\
Mortar and pestle & barley flour, rice bowl, spoon \\
Handmade snack & silkworm, reel, shuttle \\
Weaving & old textbook, pencil, school bag \\
Elementary school & knead pot, rolling pin, board \\
Making noodles &
\end{tabular}

In the beginning, the reality orientation method was executed, which provided hints and signs to reconfirm the subjects' orientation in terms of time and date. Then, the reminiscence therapy method was executed. In reminiscence therapy, old-style tools such as a rice kettle, beanbags for juggling, and old textbooks were used, and staff asked the participants about the names of the tools and how to use them. Tools that are familiar to participants provide visual support for enhancing reminiscence. In addition, these tools encompass many activities, from housework to recreation, such as handiwork. These activities using old-style tools recruit procedural memories, which remain after the loss of episodic memory. Therefore, participants gain peace of mind, as they can easily relate to and describe these tools (the fifth principle: supportive care). The participants teach staff how to use these old-style tools. This is role reversal: the participants are teaching the staff who help them in daily living. Through this process, participants were expected to recover their self-confidence and the social function of passing on knowledge to younger generations (the fourth principle: social role). Because of this role reversal, the staff took care to praise the participants naturally (the third principle: praising). Thus, it is expected that participants enjoy the conversations. The control group had no treatment.

Outcome Measures

Care staff who did not participate in the intervention primarily evaluated participants using two observation scales which were primary outcomes: clinical dementia rating (CDR) [9] and multidimensional observation scale for elderly subjects (MOSES) [10]. CDR is reported to have high reliability (internal consistency: $0.68-0.88$ ). Global severity of dementia was evaluated by the sum of boxes in CDR (CDR-SB) [11]. The CDR-SB sums the ratings in each of six domains ('boxes') of CDR to provide a consensus-based global clinical measure. MOSES is reported to have high reliability (internal consistency: 0.78-0.87). The scale is comprised of 40 parameters in 5 categories of daily life functions: (1) self-care; (2) disorientation; (3) depression; (4) irritability, and (5) withdrawal. Each category's score distribution ranges from 8 to 32 points $(1=$ not at all; $2=$ seldom; $3=$ at times; $4=$ often $)$ with higher scores indicating more severe disorders [10].

The participants underwent two cognitive tests, which are secondary outcomes: HDS-R and trail making test A [12]. HDS-R was performed to assess global cognitive function. HDS$\mathrm{R}$ correlates well with MMSE, and it is more accurate than MMSE in diagnosing Alzheimer's disease [13]. In addition, HDS-R was shown to be more robust to demographic influences 
(age, education level, and gender) than MMSE [14]. Trail making test A was used to evaluate psychomotor speed. Participants were asked to draw a continuous line connecting 25 numbered circles.

After the intervention period, we prepared two questions for staff members: did the participants change after intervention and, if so, how? Did your daily care with the participants change in terms of both physical care and social contact?

\section{Procedure}

This study was approved by the Institutional Research Board of Takasaki University of Health and Welfare (No. 2201). Written consent was obtained from each participant and their families after providing full information regarding the purpose of this study, the risks and benefits, confidentiality, anonymity, and freedom of participation. Participants in the control group were assured that they would receive the same intervention after the intervention period.

\section{Statistical Analysis}

Data of outcome measures before and after intervention were analyzed using the Japanese version of SPSS Statistics for Windows version 18.0 (IBM Corporation, New York, N.Y., USA). Mann-Whitney U test and Fisher's exact test were used for comparison of the two groups at baseline. The primary and secondary statistical hypothesis was that the two observation scales and two cognitive tests would be improved in the intervention group compared with the control group after the intervention period. Repeated measures analysis of covariance (ANCOVA) with the covariates of age and sex was used to analyze the participants at the end of the study. Post hoc analysis for 'between participants' and 'within participants' was conducted with Bonferroni correction.

'Yes' and 'no' answers from the staff were analyzed. Free descriptions were separated into clauses to extract relevant words. We categorized similar words as the same opinion. We counted the number of words in each category.

\section{Results}

\section{Baseline Characteristics of the Participants}

The study participants were 54 elderly people with dementia (28 in the intervention group and 26 in the control group). No significant difference was found at baseline in any of the demographic variables (table 2).

In the intervention group, no participants dropped out and all took part in $\geq 20$ of the total of 24 sessions. They looked cheerful and the average attendance rate was high (95.5\%). In the control group, 1 participant dropped out due to sickness during the intervention period. Finally, outcome measures were analyzed in 53 participants: 28 participants in the intervention group and 25 in the control group, who completed the second evaluation.

\section{Change in the Outcome Measures (table 3)}

Repeated measure ANCOVA showed a significant interaction for total score of CDR$\mathrm{SB}(\mathrm{F}(1,49)=7.190, \mathrm{p}=0.015)$. The control group showed significant deterioration of CDR$\mathrm{SB}(\mathrm{p}=0.016)$. On the other hand, the intervention group showed maintenance of this score.

Repeated measure ANCOVA showed a significant interaction for the total score of MOSES $(\mathrm{F}(1,49)=4.525, \mathrm{p}=0.038)$, subscale of disorientation $(\mathrm{F}(1,49)=6.453, \mathrm{p}=0.014)$ and withdrawal $(\mathrm{F}(1,49)=4.955, \mathrm{p}=0.031)$ in daily life functions. In the post hoc analysis, the 
Yamagami et al.: A Randomized Controlled Trial of Brain-Activating Rehabilitation for

Elderly Participants with Dementia in Residential Care Homes

Table 2. Demographics of the study participants $(n=54)$

\begin{tabular}{lccc}
\hline & Intervention group $(\mathrm{n}=28)$ & Control group $(\mathrm{n}=26)$ & $\mathrm{p}$ \\
\hline Age, years & $85.5 \pm 4.0$ & $84.9 \pm 6.5$ & 0.652 \\
Gender & $1(3.6)$ & $4(15.4)$ & \\
$\quad$ Male & $27(96.4)$ & $22(84.6)$ & 0.153 \\
$\quad$ Female & & & \\
Diagnosis & & \\
$\quad$ AD & $18(64.3)$ & $16(61.5)$ & \\
VD & $1(3.6)$ & $3(11.5)$ & 0.334 \\
AD and VD mixed & $2(7.1)$ & $0(0.0)$ & \\
FTD & $0(0.0)$ & $2(7.7)$ & 0.403 \\
Unspecified dementia & $7(25.0)$ & $5(19.2)$ & 0.131 \\
Donepezil prescribed & $9(32.1)$ & $12(46.2)$ & \\
Psychotropics prescribed & $5(17.9)$ & $10(38.5)$ & 0.314 \\
Mobility & & & \\
Independence & $14(50.0)$ & $15(57.7)$ & \\
Walking aids & $9(32.1)$ & $5(19.2)$ & \\
$\quad$ Wheelchair & $5(17.9)$ & $6(23.1)$ & \\
CDR & $4(14.3)$ & $5(19.2)$ & \\
$\quad$ 0.5 (questionable) & $15(53.6)$ & $9(34.6)$ & \\
1 (mild) & $7(25.0)$ & $10(38.5)$ & \\
2 (moderate) & $2(7.1)$ & $2(7.7)$ & \\
3 (severe) & & & \\
\hline
\end{tabular}

Values are means \pm SD or numbers with percentages in parentheses. Mann-Whitney U test or Fisher's exact test were used. $\mathrm{AD}=$ Alzheimer's disease $; \mathrm{VD}=$ vascular dementia; $\mathrm{FTD}=$ frontotemporal dementia. ${ }^{a}$ Clinical diagnosis assigned according to the notes of participants' consultant physicians.

control group showed a tendency of deterioration (subscale of disorientation, $p=0.054$, and withdrawal, $p=0.095$ ), but there was no significant difference. The intervention group had significantly lower scores for total score of MOSES $(p=0.048)$ and subscale of withdrawal $(\mathrm{p}=0.008)$ than the control group after intervention.

There were no significant effects on the two cognitive tests of HDS-R and trail making test A.

\section{Staff Interview}

In terms of changes seen in the intervention group, 26 (63.4\%) of the 41 staff members noticed a positive change. Staff opinions were as follows: 'improved peer relationships' ( $\mathrm{n}=$ $12)$, 'a more cheerful and positive outlook' $(n=11)$, 'positive anticipation of session' $(n=6)$, and 'co-operative attitude toward the care staff' $(\mathrm{n}=4)$. In terms of changes in staff, 31 (75.6\%) of the 41 staff members noticed a change. Staff opinions were as follows: 'I began to listen to the participants' recollections of their younger days' $(\mathrm{n}=16)$, 'I learned how to communicate with the participants in a positive manner' $(n=10)$, 'I learned the importance of role reversal by being taught new things by the participants' $(n=6)$, 'I noticed for the first time the abilities of the participants' $(n=4)$, and 'I learned the importance of expressing appreciation when tasks are completed well' $(\mathrm{n}=3)$. 
Table 3. Change in outcome measures for the intervention $(n=28)$ and control groups $(n=25)$

\begin{tabular}{|c|c|c|c|c|c|c|c|}
\hline \multirow[t]{3}{*}{ Outcome variable } & \multicolumn{4}{|l|}{ Time period } & \multirow{2}{*}{\multicolumn{2}{|c|}{ Interaction }} & \multirow{3}{*}{$\begin{array}{l}\text { Post hoc } \\
\text { analysis }\end{array}$} \\
\hline & \multicolumn{2}{|l|}{ before test } & \multicolumn{2}{|l|}{ after test } & & & \\
\hline & mean $\pm \mathrm{SD}$ & $\mathrm{p}$ & mean $\pm \mathrm{SD}$ & $\mathrm{p}$ & $\mathrm{F}$ & $\mathrm{p}$ & \\
\hline \multicolumn{8}{|l|}{ CDR-SB } \\
\hline Intervention & $8.0 \pm 3.8$ & \multirow{2}{*}{0.684} & $7.6 \pm 3.5$ & \multirow{2}{*}{0.200} & \multirow{2}{*}{7.190} & \multirow{2}{*}{$0.015^{*}$} & 0.296 \\
\hline Control & $8.5 \pm 4.5$ & & $9.3 \pm 4.8$ & & & & $0.016^{*}$ \\
\hline \multicolumn{8}{|l|}{ MOSES total } \\
\hline Intervention & $71.4 \pm 12.7$ & \multirow{2}{*}{0.200} & $69.3 \pm 15.4$ & \multirow{2}{*}{$0.048^{*}$} & \multirow{2}{*}{4.525} & \multirow{2}{*}{$0.038^{*}$} & 0.105 \\
\hline Control & $76.8 \pm 16.4$ & & $78.7 \pm 16.6$ & & & & 0.168 \\
\hline \multicolumn{8}{|l|}{ MOSES self-care } \\
\hline Intervention & $14.0 \pm 4.1$ & \multirow{2}{*}{0.226} & $13.8 \pm 5.2$ & \multirow{2}{*}{0.186} & \multirow{2}{*}{0.405} & \multirow{2}{*}{0.527} & 0.692 \\
\hline Control & $15.7 \pm 5.7$ & & $15.9 \pm 5.8$ & & & & 0.612 \\
\hline \multicolumn{8}{|c|}{ MOSES disorientation } \\
\hline Intervention & $18.8 \pm 4.1$ & \multirow{2}{*}{0.964} & $18.2 \pm 4.6$ & \multirow{2}{*}{0.407} & \multirow{2}{*}{6.453} & \multirow{2}{*}{$0.014^{*}$} & 0.105 \\
\hline Control & $18.6 \pm 6.1$ & & $19.4 \pm 6.4$ & & & & 0.054 \\
\hline \multicolumn{8}{|l|}{ MOSES depression } \\
\hline Intervention & $11.2 \pm 3.4$ & \multirow{2}{*}{0.394} & $10.9 \pm 3.2$ & \multirow{2}{*}{0.521} & \multirow{2}{*}{0.101} & 0752 & 0.602 \\
\hline Control & $12.0 \pm 4.9$ & & $11.5 \pm 5.0$ & & & 0.152 & 0.353 \\
\hline MOSES irritability & & & & & & & \\
\hline Intervention & $11.0 \pm 2.7$ & 0926 & $10.8 \pm 3.2$ & 0.488 & 1159 & 0287 & 0.630 \\
\hline Control & $11.3 \pm 2.8$ & 0.920 & $11.7 \pm 3.3$ & 0.480 & 1.109 & $0.28 /$ & 0.303 \\
\hline MOSES withdrawa & & & & & & & \\
\hline Intervention & $16.4 \pm 5.4$ & 0 & $15.5 \pm 5.7$ & $0008 *$ & 4055 & $0031^{*}$ & 0.146 \\
\hline Control & $19.1 \pm 5.4$ & 0.104 & $20.2 \pm 5.4$ & 0.000 & 4.935 & 0.031 & 0.095 \\
\hline HDS-R & & & & & & & \\
\hline Intervention & $13.1 \pm 4.5$ & 0760 & $13.4 \pm 4.6$ & 0002 & 0078 & 078 & 0.722 \\
\hline Control & $12.6 \pm 5.8$ & $0 . / 08$ & $13.0 \pm 6.2$ & 0.903 & 0.078 & $0 . / 81$ & 0.470 \\
\hline TMT-A & & & & & & & \\
\hline Intervention & $177.9 \pm 94.7$ & 0.300 & $171.2 \pm 96.6$ & 0.252 & 0.128 & 0.722 & 0.901 \\
\hline Control & $218.2 \pm 118.5$ & 0.300 & $229.6 \pm 145.1$ & & & & 0.707 \\
\hline
\end{tabular}

Repeated measures ANCOVA with the covariates of age and sex was used, and post hoc analysis with Bonferroni correction was conducted. TMT-A = Trail making test A. ${ }^{*} \mathrm{p}<0.05$.

\section{Discussion}

The results indicate the effect of intervention based on the principles of BAR on the improvement or maintenance of two observation scales, CDR-SB and MOSES, especially disorientation and withdrawal, although no improvement was shown in terms of the two cognitive tests of HDS-R and trail making test A. In a previous randomized controlled trial, the effect of a group care program, which consisted of reminiscence and reality orientation, was examined using an observation scale (MOSES) and a cognitive test (MMSE) as outcome measures [15]. The study found improved orientation and withdrawal subscales of MOSES, agreeing with our current study. In a randomized controlled trial on 168 demented elders in nursing homes, a comprehensive program of counseling, life review, interpersonal therapy, behavioral therapy, and rehabilitation reduced multiple psychiatric symptoms, suggesting the importance of a person-oriented approach [16]. Activities adjusted to 'personality style of interest' reduced agitation and passivity of demented elders. Furthermore, the activities adjusted to both functional level and personality style of interest brought greater pleasure 
than activities partially adjusted or non-adjusted to individual preferences and needs [17]. In the current study, we tried to adapt the contents of the sessions to each participant by collecting information on life history, although intervention sessions were conducted in a group setting.

Due to the basis of the 5 principles of BAR, participants looked cheerful and the average attendance was extremely high (95.5\%). When the staff took care of the participants by following the principles of BAR, staff became more receptive and provided care that encouraged demonstration of each participant's abilities. The responses to questions by the staff also supported these findings. Intervention with BAR principles enhanced understanding between staff and participants, as well as between participants [6]. The benefit was generalized to participants' daily life. Therefore, participants may gain a sense of self-worth and a desire to live, and the behavioral and psychological symptoms of the participants may be reduced. In fact, in this study, withdrawal was alleviated. Intervention following the BAR principles also improved apathy and social ability in elderly participants with mild cognitive impairment and mild dementia [18]. The concept of person-centered care can be described as follows: it acknowledges that the individual is a person who can experience life and relationships, despite progressive disease; involves inclusion of the person's past life and history in their care, and it focuses on what the person can do, rather than abilities that have been lost owing to the disease [19]. The concept of person-centered care is widely accepted in the field of dementia care. BAR is also a concept but not a technique. We expect BAR to be widely accepted in the field of dementia rehabilitation.

Our randomized controlled trial revealed that intervention based on BAR principles promoted intersubjectivity between participants and therapists/care staff and was effective for maintaining and improving emotional and daily life functions in the current study. Participants may regain their confidence. BAR principles of enjoyable stimulation, communication, and role reversal contribute to providing an environment where elderly participants with dementia can laugh and be themselves.

We revealed the effectiveness of dementia rehabilitation based on the principles of BAR by a randomized controlled trial. A pleasant atmosphere, communication, praising, social role, and supportive care are essential in rehabilitation for dementia.

\section{Acknowledgements}

We thank the participants in this study, as well as the care staff in residential care homes, for their contribution. T.Y. was supported by a Grant-in-Aid for Scientific Research from the Ministry of Education, Science, Sports, Culture and Technology, Japan (22700529). H.Y. is supported by Grants-in-Aid for Scientific Research from the Ministry of Education, Science, Sports, Culture and Technology, Japan (23300197 and 22650123), and a Grant-in-Aid for Scientific Research (H22-Ninchisho-Ippan-004) from the Ministry of Health, Labor and Welfare of Japan.

\section{Disclosure Statement}

The authors declare that they have no conflicts of interest. 


\section{References}

1 Woods B, Spector A, Jones C, Orrell M, Davies S: Reminiscence therapy for dementia. Cochrane Database Syst Rev 2005;CD001120.

2 Neal M, Briggs M: Validation therapy for dementia. Cochrane Database Syst Rev 2003;CD001394.

3 Clare L, Woods RT, Moniz Cook ED, Orrell M, Spector A: Cognitive rehabilitation and cognitive training for early-stage Alzheimer's disease and vascular dementia. Cochrane Database Syst Rev 2003;CD003260.

-4 Haslam C, Haslam SA, Jetten J, Bevins A, Ravenscroft S, Tonks J: The social treatment: the benefits of group interventions in residential care settings. Psychol Aging 2010;25:157-167.

-5 Yamaguchi H, Maki Y, Yamagami T: Overview of non-pharmacological intervention for dementia and principles of brain-activating rehabilitation. Psychogeriatrics 2010;10:206-213.

-6 Yamagami T, Oosawa M, Ito S, Yamaguchi H: The effect of activity reminiscence therapy as brainactivating rehabilitation for elderly people with and without dementia. Psychogeriatrics 2007;7:6975 .

-7 Yamaguchi H, Maki Y, Takahashi K: Rehabilitation for dementia using enjoyable video-sports games. Int Psychogeriatr 2011;23:674-676.

8 Kato S, Shimogaki H, Onodera A, Ueda H, Oikawa K, Ikeda K, Kosaka A, Imai Y, Hasegawa K: Development of the revised version of Hasegawa's Dementia Scale (HDS-R) (in Japanese). Jpn J Geriatric Psychiatry 1991;2:1339-1347.

-9 Hughes CP, Berg L, Danziger WL, Coben LA, Martin RL: A new clinical scale for the staging of dementia. Br J Psychiatry 1982;140:566-572.

-10 Helmes E, Csapo KG, Short JA: Standardization and validation of the multidimensional observation scale for elderly subjects (MOSES). J Gerontol 1987;42:395-405.

-11 Berg L, Miller JP, Storandt M, Duchek J, Morris JC, Rubin EH, Burke WJ, Coben LA: Mild senile dementia of the Alzheimer type: 2. Longitudinal assessment. Ann Neurol 1988;23:477-484.

12 Reitan RM: Validity of the Trail Making test as an indicator of organic brain damage. Percept Mot Skills 1958;8:271-276.

-13 Kim KW, Lee DY, Jhoo JH, Youn JC, Suh YJ, Jun YH, Seo EH, Woo JI: Diagnostic accuracy of MiniMental Status Examination and Revised Hasegawa Dementia Scale for Alzheimer's disease. Dement Geriatr Cogn Disord 2005;19:324-330.

14 Jeong JW, Kim KW, Lee DY, Lee SB, Park JH, Choi EA, Choe JY, Do YJ, Ryang JS, Roh HA, Park YS, Choi Y, Woo JI: A normative study of the Revised Hasegawa Dementia Scale: comparison of demographic influences between the Revised Hasegawa Dementia Scale and the Mini-Mental Status Examination. Dement Geriatr Cogn Disord 2007;24:288-293.

-15 Tadaka E, Kanagawa K: A randomized controlled trial of a group care program for communitydwelling elderly people with dementia. Jpn J Nurs Sci 2004;1:19-25.

-16 Bakker TJ, Duivenvoorden HJ, van der Lee J, Olde Rikkert MG, Beekman AT, Ribbe MW: Integrative psychotherapeutic nursing home program to reduce multiple psychiatric symptoms of cognitively impaired patients and caregiver burden: randomized controlled trial. Am J Geriatr Psychiatry 2011; 19:507-520.

-17 Kolanowski A, Litaker M, Buettner L, Moeller J, Costa PT Jr: A randomized clinical trial of theorybased activities for the behavioral symptoms of dementia in nursing home residents. J Am Geriatr Soc 2011;59:1032-1041.

18 Yamagami T, Fujita K, Koiwai A, Sekiguchi N, Kaburagi S, Umezawa A, Maita S, Yamaguchi H: Effects of brain-activating rehabilitation in preventing the initiation and progression of dementia (in Japanese). Jpn J Geriatric Psychiatry 2010;21:893-898.

19 Kitwood T: Dementia Reconsidered: The Person Comes First. Buckingham, Open University Press, 1997. 